\title{
CIUDADANÍA DEMOCRÁTICA vS. IDENTIDAD NACIONAL: LOS DERECHOS POLÍTICOS DE LOS EXTRANJEROS EN ESPAÑA
}

\author{
DEMOCRATIC CITIZENSHIP vs. NATIONAL IDENTITY: THE POLITICAL \\ RIGHTS OF FOREIGNERS IN SPAIN
}

\author{
Antonia Durán Ayago \\ Universidad de Salamanca, España/Spain \\ aduran@usal.es
}

Recibido/Received: 14/01/2015

Modificado/Modified: 16/04/2015

Aceptado/Accepted: 29/04/2015

\begin{abstract}
RESUMEN
La relación entre soberanía-pueblo-nacionalidad-ciudadanía debe ser objeto de revisión. La ciudadanía democrática, único concepto válido en el siglo XXI, implica que todas las personas, con independencia de su origen, puedan tener una implicación directa en los asuntos de la vida pública que le conciernen. En España, este derecho sólo lo poseen los ciudadanos de la Unión Europea en las elecciones municipales y al Parlamento Europeo, y los nacionales de los 12 países con los que España ha firmado Acuerdos, y únicamente para ejercer el derecho de sufragio activo en las elecciones municipales. Esto supone que en las próximas elecciones municipales de mayo de 2015 , únicamente el $15 \%$ de los extranjeros no nacionales de la Unión Europea que residen en nuestro país podrán ejercer el derecho de sufragio.
\end{abstract}

\section{PALABRAS CLAVE}

Nacionalidad, extranjero, derechos fundamentales, derechos políticos, sufragio activo y pasivo.

\section{SUMARIO}

I. Introducción. II. Contexto jurídico de los derechos políticos de los extranjeros en España. 1. Contexto internacional. 2. Contexto interno. A) Constitución española y Ley de Extranjería. B) Convenios bilaterales. C) Regulación de la Unión Europea. D) Régimen electoral. III. Análisis de las "fracasadas" Propuestas legislativas de reconocimiento del derecho de sufragio a los ciudadanos extranjeros en España. IV. Derecho Comparado. V. Conclusiones. Bibliografía.

\begin{abstract}
The relationship between sovereignty-people-nationality-citizenship should be revised. Democratic citizenship, only valid in the 21st century concept implies that all people, regardless of their origin, could have direct involvement in the affairs of public life that concerns you. In Spain, this right only possessed by citizens of the European Union in local elections and the European Parliament, and nationals of the 12 countries with which Spain has signed agreements, and only for exercising the right to vote in elections municipal. This means that in the upcoming municipal elections of May 2015, only $15 \%$ of non-national EU foreigners residing in our country may exercise the right to vote.
\end{abstract}

\section{KEYWORDS}

Nationality, foreigner, fundamental rights, political rights, vote. 


\section{CONTENTS}

I. Introduction. II. Legal context of the political rights of foreigners in Spain. 1. International context. 2. Internal context. A) Spanish Constitution and Immigration Law. B) Bilateral Agreements. C) Regulation of the European Union. D) Electoral System. III. Analysis of "failed" Legislative Proposals recognition of the right of vote to foreign citizens in Spain. IV. Comparative Law. V. Conclusions. References.

\section{INTRODUCCIÓN}

España se incorporó tarde al debate en torno al reconocimiento del derecho de sufragio activo y pasivo a los inmigrantes nacionales de terceros países. Y con ello nos referimos a los nacionales de Estados no miembros de la Unión Europea, ya que los nacionales de los Estados miembros de la Unión tienen reconocido este derecho en las elecciones municipales y al Parlamento Europeo desde el Tratado de Maastricht de 1992, como más adelante precisaremos. El debate se activó a partir del 27 de septiembre de 2005, fecha en que se presentó una Proposición de Ley Orgánica para el reconocimiento del derecho de sufragio activo y pasivo a los ciudadanos extranjeros en España (BOGC Serie B Proposiciones de Ley, núm. 207-1, de 7 de octubre de 2005). Pero lejos de hacerlo con amplitud de miras, se planteó en unos términos reduccionistas, sin divisar que quizás fuera necesario modificar los anacrónicos límites de la Constitución española en esta materia, puesto que aunque las propuestas de reforma han apostado por remover los estrictos límites de la reciprocidad presentes en la Ley Orgánica de Extranjería, su permanencia en la Constitución puede llevar a que se susciten dudas que en nada facilitan el camino para el reconocimiento de este derecho a los extranjeros.

La relación entre soberanía-pueblo-nacionalidad-ciudadanía ha sido una secuencia que se ha presentado con toda lógica durante el siglo XIX y buena parte del XX (Méndez Lago: 126). Sin embargo, anudar a la nacionalidad el concepto de ciudadanía, concebida ésta como capacidad de participación en la gestión de los asuntos públicos, siendo únicamente el ciudadano-nacional el que tiene derecho a postularse como representante en las instancias públicas y a elegir a quiénes van a representarlo en el campo político, no sólo es una secuencia que ha ido perdiendo racionalidad, sino que exige una reformulación más adaptada a los tiempos. Lo cierto es que una profundización en la idea de democracia exige romper esos estrictos moldes para dar cabida a la intervención de los ciudadanos, independientemente de su nacionalidad, en la vida política y pública puesto que son parte de esa vida. Y es que como señala Habermas, "la ciudadanía democrática no necesita quedar enraizada en la identidad nacional de un pueblo".

En realidad, la identidad conceptual entre nacionalidad y ciudadanía ha sido el resultado de un proceso histórico de construcción que ha concluido con la exclusión de ciertas categorías de individuos de su status privilegiado (Closa, 1995:487 y ss.). Se ha logrado la identidad entre nacionales y ciudadanos, se ha dado a todos ellos la capacidad de participar en los asuntos públicos en condiciones de igualdad, y se ha excluido únicamente del ejercicio de la ciudadanía a los no nacionales.

Es verdad que todavía hoy, la desnacionalización de la ciudadanía política es un proceso parcial y muy limitado (Miravet, 2006:4) y que la desagregación de la condición ciudadana (ruptura del vínculo nacionalidad-derechos) tiene su contrapunto en la denominada “estratificación cívica” (Morris, 2002), cuya prueba más evidente es la multiplicación de 
regímenes de derechos reconocidos a los extranjeros en función del tipo de permiso o autorización que posean, convirtiendo al fenómeno migratorio en una comprensión abiertamente instrumental.

Sin embargo, la inmigración ha dejado de ser una cuestión sólo económica para adquirir un significado también político que plantea nuevos retos a la concepción estadocéntrica de las identidades políticas (Miravet, 2006:2). Y ya se empieza a insistir desde el Derecho Constitucional en que la participación electoral de los no nacionales debe ponerse en relación con el principio de la plena realización del hombre y con la garantía constitucional del respeto a la dignidad personal (Esteban de la Rosa: 2; Presno Linera, 2004). En este sentido de hilar la dignidad humana con el derecho de participación política, ha incidido la trascendental sentencia del Tribunal Constitucional 236/2007, de 7 de noviembre, que avanza en su doctrina anterior incorporando la novedad de analizar el grado de conexión de cada derecho con la dignidad de la persona, lo que se ha calificado como construcción jurídica sólida, pero de difícil aplicación práctica. Según dicha sentencia, resulta decisivo determinar el grado de conexión con la dignidad humana que mantiene un derecho concreto, ya que el legislador goza de una limitada libertad de configuración al regular los derechos imprescindibles para la garantía de la dignidad humana. En la STC 91/2000 indica que se debe partir en cada caso del tipo abstracto de derecho y de los intereses que básicamente protege para precisar si y en qué medida son inherentes a la dignidad de la persona humana concebida como un sujeto de derecho, es decir, como miembro libre y responsable de una comunidad jurídica que merezca ese nombre y no como mero objeto del ejercicio de los poderes públicos (fj. 7).

Por ello, es necesario evitar caer en el error de considerar que la concesión del derecho al voto al inmigrante se entienda como una cesión de privilegios de los nacionales de un país a los inmigrantes, con la consiguiente preocupación del uso que puedan realizar individual o colectivamente del mismo. Al contrario, debe considerarse como un derecho innato del ser humano a participar en asuntos que como miembro de una comunidad (a nivel local, nacional o supranacional) le compete. La efectiva y completa integración del inmigrante debe suponer el hecho de que sean tenidos en cuenta como un miembro más, no como privilegiados que han conseguido obtener el derecho de sufragio (Biedma Ferrer, 1995:2).

\section{CONTEXTO JURÍDICO DE LOS DERECHOS POLÍTICOS DE LOS EXTRANJEROS EN ESPAÑA}

Para concretar cuál es el escenario jurídico en el que se enmarca el derecho de sufragio de los inmigrantes no europeos en España, en primer lugar, nos vamos a referir al contexto internacional, incidiendo en la regulación que los principales Convenios relativos a los Derechos Humanos realizan sobre el derecho de sufragio. A continuación, analizaremos la regulación constitucional y su desarrollo en la Ley de Extranjería, incidiendo también en la regulación convencional de la que España es parte. Finalmente, haremos referencia también a cuál es la situación de los ciudadanos de la Unión Europea en nuestro país en lo relativo al derecho de sufragio.

\section{Contexto internacional}

Un rápido recorrido por las principales normas internacionales reguladoras de los derechos fundamentales nos pone de manifiesto que la Declaración Universal de los Derechos del Hombre de 1948 no reconoce a los extranjeros el derecho a tomar parte de los 
asuntos públicos; la Convención Europea de Protección de los Derechos del Hombre y de las Libertades fundamentales de 1950 declara expresamente la libertad de los Estados de imponer restricciones a la actividad política de los extranjeros; la Convención americana relativa a los Derechos del Hombre de 1969 reserva expresamente a los ciudadanos en tanto nacionales la participación en los asuntos públicos, tal y como prevé también el artículo 25 del Pacto Internacional de Derechos Civiles y Políticos de 1966. De manera que lejos de servir a una mayor extensión de los derechos políticos, el Derecho Internacional ha coadyuvado a legitimar la situación de rechazo del acceso de los extranjeros a los derechos políticos (Esteban de la Rosa, 2001: 3).

Sin embargo, hay otros datos que animan al optimismo. Así, en el Dictamen del Comité Económico y Social Europeo 593/2003, sobre incorporación a la ciudadanía de la Unión Europea, se solicita que se otorgue la ciudadanía no sólo a los nacionales de los Estados miembros, sino también a todas las personas que residan de manera estable en la Unión Europea, de forma que éstas puedan ejercer su derecho de sufragio (activo y pasivo) en las elecciones al Parlamento Europeo y también en las municipales, en el lugar de su residencia.

Por su parte, la Comisión de Venecia (European Commission for Democracy through law), creada en el seno del Consejo de Europa, en el Informe sobre la eliminación de restricciones al derecho de voto en las elecciones generales, considera que el reconocimiento del derecho de voto a los extranjeros residentes de larga duración puede considerarse una cuestión de estricta justicia, teniendo en cuenta que contribuyen al desarrollo de su comunidad de residencia.

Y el Convenio sobre la participación de los extranjeros en la vida pública a nivel local, hecho por el Consejo de Europa en Estrasburgo el 5 de febrero de 1992, prevé la concesión del derecho de sufragio activo y pasivo en las elecciones municipales a todo extranjero que resida legalmente en el país, sin que el ejercicio de este derecho quede sometido a condición de reciprocidad. Este Convenio representa un hito sin precedentes en la universalización de los derechos políticos, pues supone un compromiso de concesión del derecho de sufragio activo y pasivo en las elecciones locales a todo extranjero con residencia legal.

Finalmente, el Tratado de Funcionamiento de la Unión Europea reconoce el derecho de sufragio activo y pasivo, en las elecciones municipales y al Parlamento Europeo de los nacionales de la Unión Europea que residan en otro país de la Unión del cual no sean nacionales. En este caso, el derecho electoral es reconocido sobre la base de una reciprocidad institucional y sólo y exclusivamente a los extranjeros que sean nacionales de un Estado perteneciente a la Unión Europea. En este caso, además, el concepto de extranjero queda matizado pues todos los ciudadanos nacionales de un Estado miembro de la Unión Europea gozan de la ciudadanía europea (artículo 20 TFUE).

\section{Contexto interno}

\section{A) Constitución española y Ley de Extranjería}

En España, son dos los textos principales que abordan la regulación de esta cuestión. De un lado, la Constitución española, en sus artículos 13 y 23 y, de otro, la Ley Orgánica 4/2000, de 11 de enero, sobre derechos y libertades de los extranjeros en España y su integración social (reformada por las Leyes Orgánicas 8/2000, 14/2003, 2/2009, 10/2011 y por el Real Decreto Ley 16/2012), en su artículo 6.

Según el artículo $23 \mathrm{CE}$, "los ciudadanos tienen el derecho a participar en los asuntos públicos, directamente o por medio de representantes, libremente elegidos en elecciones periódicas por sufragio universal. Asimismo, tienen derecho a acceder en condiciones de igualdad a las funciones y cargos públicos, con los requisitos que señalen las leyes". 
Ciertamente, en este precepto no se alude a la nacionalidad española, sino a los ciudadanos, sin precisar quiénes deben ser considerados como tales. Sin embargo, el artículo 13.2 CE precisa que "solamente los españoles serán titulares de los derechos reconocidos en el artículo 23, salvo lo que, atendiendo a criterios de reciprocidad, pueda establecerse por tratado o ley para el derecho de sufragio activo y pasivo en las elecciones municipales".

Varias cuestiones son susceptibles de ser reseñadas en este último precepto. En primer lugar, la referencia a la nacionalidad española ('solamente los españoles') como presupuesto de la titularidad subjetiva del derecho de sufragio activo y pasivo. En segundo lugar, la apertura de este derecho, atendiendo a criterios de reciprocidad, a los nacionales de terceros países. En tercer lugar, esta reciprocidad se puede establecer a través de tratado o de ley. Y en cuarto lugar, únicamente cabrá reconocer este derecho en los términos antedichos en las elecciones municipales. Dado que el tratamiento de los nacionales de la Unión Europea tiene su singularidad, lo abordaremos más adelante, fijándonos ahora únicamente en los nacionales de países no miembros de la Unión Europea.

Para explicar el artículo 13.2 CE, hay que remontarse a varios pronunciamientos del Tribunal Constitucional. En relación con la modificación que hubo que introducir en el citado precepto, para adaptarlo a las exigencias del Tratado de Maastricht, la Declaración del Tribunal Constitucional 1/1992 sobre el derecho de sufragio pasivo en las elecciones municipales, consideró que tal incorporación era compatible con el artículo 1.2, en el que se indica que "la soberanía nacional reside en el pueblo español del que emanan todos los poderes del Estado". Entendía el TC que no existe incompatibilidad por considerar que los municipios no ostentan potestades atribuidas directamente por la Constitución y los Estatutos de Autonomía y ligadas a la titularidad de la soberanía por el pueblo español. De manera que la participación de los extranjeros en las elecciones locales o municipales suele ser explicada por razón del carácter meramente administrativo, y no político, de la autonomía municipal, y por la marginación de los entes locales de los poderes soberanos del Estado (Esteban de la Rosa:3.). Es ésta una interpretación muy discutible, cuya consecuencia más notable es privar de alguna manera de contenido al derecho de sufragio activo y pasivo en las elecciones municipales, otorgándole un valor inferior que al ejercido en las elecciones autonómicas o nacionales. Y nada en la Constitución parece indicar que haya varios tipos de derecho de sufragio, en función de ante qué institución se ejerza. Por lo que no considero que el valor del voto en las elecciones municipales sea menos político que en las generales.

En atención a la doctrina del TC explicitada en su sentencia 107/1984, el derecho de sufragio activo y pasivo en las elecciones municipales sólo pertenece a los extranjeros de acuerdo con lo dispuesto por los tratados o por las leyes que reconozcan ese derecho. La extensión de este derecho a los extranjeros puede tener lugar bien mediante la conclusión por España de un tratado con otro Estado, en el que quedarán fijadas las condiciones de ejercicio del derecho por los extranjeros en España y por los españoles en el correspondiente Estado; bien por vía legal, mediante la elaboración de una ley en la cual el Estado, de forma unilateral, reconozca el derecho y establezca las condiciones para su ejercicio. En esta última vía se insertaban las frustradas iniciativas legislativas que hasta el momento se han presentado y en las que se proponía el reconocimiento del derecho de sufragio activo y pasivo en las elecciones municipales y al Parlamento Europeo a todos los residentes extranjeros que pudieren acreditar su residencia legal en España durante un tiempo determinado, según que se trataran de las elecciones municipales (un año o tengan estatuto de residentes permanentes) o al Parlamento Europeo (tres años o estatuto de residentes permanentes) (Esteban de la Rosa, 2001: 6). No obstante, la acción del Gobierno se ha 
decantado, como veremos, por la vía convencional, celebrando hasta el momento 13 Acuerdos con diversos Estados que exigen con carácter general y entre otros requisitos, para ejercer el derecho de voto en las elecciones municipales en España, la residencia legal e ininterrumpida de cinco años en nuestro país.

Sin duda, el mayor obstáculo para que los inmigrantes puedan acceder al derecho de sufragio es la exigencia constitucional de reciprocidad, esto es, que únicamente se admita este derecho cuando se establezcan por ley o tratado criterios recíprocos. Según la STC 132/1998, "el principio de reciprocidad tiene un significado jurídico preciso, consistente en que un poder público condiciona su actuación a que otro poder público, distinto y ajeno al primero, actúe de la misma manera que él, so pena de que ambos se nieguen recíprocamente lo que a los dos interesa, permaneciendo inactivos o actuando cada uno por su cuenta".

Desde un punto de vista material, la exigencia de reciprocidad del artículo 13.2 CE se traduce en que basta que los Estados en cuestión permitan el voto a los españoles en las elecciones municipales para acreditarla. Desde un punto de vista formal, se requiere la existencia de un tratado frente a la posibilidad, no utilizada aún, de apreciar reciprocidad de facto o legislativa, basada en la legislación aplicable en el Estado extranjero. Será ese tratado el que fije los concretos términos del reconocimiento del derecho de sufragio para unos y otros nacionales (Informe del Consejo de Estado sobre las propuestas de modificación del Régimen Electoral General, de 24 de febrero de 2009, p. 34).

No obstante, para avanzar en el análisis de este concepto y su influencia en el derecho de sufragio activo y pasivo, hay que recurrir al art. 6 de la Ley de Extranjería que se expresa en los siguientes términos: "Los extranjeros residentes en España podrán ser titulares del derecho de sufragio en las elecciones municipales, atendiendo a criterios de reciprocidad en los términos que por ley o tratado sean establecidos para los españoles residentes en los países de origen de aquellos". Al igual que la Ley de Extranjería de 1985, la versión del art. 6.1 de la LO 8/2000 no reconoce directamente el derecho de sufragio a los extranjeros. La finalidad de esta disposición es enunciar la posibilidad de dicha extensión de derechos y establecer ciertos límites a los desarrollos que tengan lugar por vía legal o convencional. En la versión de la LO 4/2000 había desaparecido el criterio de la reciprocidad que volvió a introducirse en la reforma de diciembre de 2000. En las Propuestas de Ley Orgánica que se han presentado para el reconocimiento del derecho de sufragio activo y pasivo a los ciudadanos extranjeros en España, que más adelante desarrollaremos, también se proponía la eliminación del criterio de reciprocidad de la Ley de Extranjería.

Ciertamente, se trata de una redacción confusa, puesto que una cosa es que la reciprocidad pueda apreciarse sin necesidad de tratado (por ejemplo, teniendo en cuenta el reconocimiento del derecho de sufragio de los españoles que pueda hacer la ley extranjera), y otra muy distinta que el reconocimiento del derecho de sufragio de los extranjeros residentes en España se haga en los términos establecidos en la ley extranjera, que es lo que dice el artículo 6 de la Ley de Extranjería.

De esta manera, parece que mientras que el artículo $13.2 \mathrm{CE}$ se inclina por la reciprocidad de reconocimiento, el artículo 6 de la Ley de Extranjería lo hace por la reciprocidad de ejercicio o, dicho con otras palabras, por una versión estricta del principio de reciprocidad. Mientras en la primera, la reciprocidad se apreciaría cuando el significado y alcance de la misma sea entendido en el sentido de su vinculación al reconocimiento por el país de procedencia del extranjero, del derecho de sufragio a favor de los españoles que allí residieran, el sentido y alcance de la reciprocidad de ejercicio atendería no sólo al reconocimiento de este derecho a los españoles en el país extranjero, sino también a las condiciones de su ejercicio, de tal modo que los criterios de reciprocidad a los que se habría 
de atender para el establecimiento del derecho exigirían, además, que las condiciones para su ejercicio por el extranjero residente fuesen iguales o similares a las establecidas para los españoles residentes en su país de procedencia. Es, por tanto, esta última una concepción más estricta, ya que exige constatar en la norma extranjera, tanto el reconocimiento del derecho para los españoles, como las condiciones para su ejercicio, y ello con el objetivo de otorgar el mismo tratamiento para el goce del derecho al extranjero en España que el que tuvieran los españoles en sus respectivos países (Sánchez Jiménez, 2009:331).

Parece compatible con la Constitución española el reconocimiento del derecho de sufragio a favor de los extranjeros con arreglo a términos distintos y a condiciones diferentes de aquéllas que se aplican a los españoles que disfrutan del derecho de sufragio en los países de origen de tales extranjeros. Así pues, la reciprocidad plasmada en el artículo 13.2 CE es una reciprocidad de reconocimiento y no de ejercicio.

En lo que respecta a la reciprocidad convencional, la reciprocidad es consustancial a su conclusión, puesto que constituye el objeto mismo del acuerdo $\mathrm{y}$, en lo que respecta a las condiciones para el ejercicio, serían las establecidas en el propio Tratado. Tratándose de reciprocidad legislativa, los criterios se deberían considerar cumplidos por el hecho de que el país extranjero en cuestión reconociera en una norma el derecho de sufragio para los españoles en las elecciones municipales.

Según el Consejo de Estado, el legislador puede optar por una reciprocidad general (frente a una reciprocidad completa), sin necesidad, por tanto, de exigir una identidad plena entre el tratamiento que los españoles reciben en el extranjero y el que se quiera dar a los extranjeros en España, en relación con el derecho de sufragio (Informe del Consejo de Estado:72).

En todo caso, admitir la reciprocidad supone negar a ciudadanos de terceros Estados no democráticos, la posibilidad de votar también en España (Informe del Consejo de Estado:63). Y debe llevarnos a ahondar en qué se pretende reconociendo el derecho de sufragio a los nacionales de un tercer Estado; si un mero intercambio de favores entre Estados (que no parece otro el sentido de la reciprocidad), o la consideración de ciudadano a toda persona que resida en un Estado, con el consecuente derecho a decidir sobre todas aquellas cuestiones que le atañen.

\section{B) Convenios bilaterales}

En realidad, la poca operatividad tanto del artículo $13.2 \mathrm{CE}$ como de su desarrollo legislativo a través del artículo 6.1 de la Ley de Extranjería se atestigua por la exigua plasmación de los postulados en textos concretos, no ya en la Ley Orgánica del Régimen Electoral General en que sólo se hace referencia al derecho de sufragio activo y pasivo en las elecciones municipales y al Parlamento Europeo de los ciudadanos de la Unión Europea, sino en el todavía escaso número de Convenios que afrontan el reconocimiento de este derecho desde la reciprocidad.

Al primer Acuerdo celebrado en este sentido por España con Noruega el 6 de febrero de 1990 (BOE núm. 153, de 27 de junio de 1991), que únicamente reconoce el derecho de sufragio activo en las elecciones municipales de los noruegos en España y de los españoles en Noruega, le han seguido en los últimos años doce acuerdos cuyo objetivo es contribuir a una mejor integración y participación de los ciudadanos de los respectivos países en sus municipios de residencia. Y es que en una intensa agenda diplomática, el Consejo de Ministros aprobó durante el año 2009 (con fechas de 16 de enero; 6, 13 y 20 de febrero; 3 y 17 de abril; 12 de junio; 11 de septiembre) distintos Acuerdos por los que se autorizan canjes de notas constitutivos de Acuerdos bilaterales de España con Colombia (Canje de Notas 
constitutivo de Acuerdo entre el Reino de España y la República de Colombia, sobre participación en las elecciones municipales de los nacionales de cada país residentes en el territorio del otro, hecho en Madrid el 5 de febrero de 2009) (BOE núm. 18, de 21 de enero de 2010), Perú (Canje de Notas, de fecha 6 de febrero de 2009, constitutivo de Acuerdo entre el Reino de España y la República del Perú sobre participación en las elecciones municipales de los nacionales de cada país residentes en el territorio del otro) (BOE núm. 122, de 19 de mayo de 2010), Trinidad y Tobago (Canje de Notas constitutivo de Acuerdo entre el Reino de España y la República de Trinidad y Tobago sobre participación en las elecciones municipales de los nacionales de cada país residentes en el territorio del otro, hecho en Puerto España el 17 de febrero de 2009) (BOE núm. 290, de 2 de diciembre de 2011), Ecuador (Canje de Notas constitutivo de Acuerdo entre el Reino de España y la República del Ecuador sobre participación en las elecciones municipales de los nacionales de cada país residentes en el territorio del otro, hecho en Quito el 25 de febrero de 2009) (BOE núm. 4, de 5 de enero de 2010), Islandia (Canje de Notas constitutivo de Acuerdo entre el Reino de España y la República de Islandia sobre participación en las elecciones municipales de los nacionales de cada país residentes en el territorio del otro, hecho en Madrid y París el 31 de marzo de 2009) (BOE núm. 305, de 16 de diciembre de 2010), Cabo Verde (Canje de Notas constitutivo de Acuerdo entre el Reino de España y la República de Cabo Verde sobre participación en las elecciones municipales de los nacionales de cada país residentes en el territorio del otro, hecho en Praia el 8 de abril de 2009) (BOE núm. 11, de 13 de enero de 2011), Chile (Canje de Notas, de 12 de mayo de 2009, constitutivo de Acuerdo entre el Reino de España y la República de Chile sobre participación en las elecciones municipales de los nacionales de cada país residentes en el territorio del otro) (BOE núm. 35, de 9 de febrero de 2010), Paraguay (Canje de Notas constitutivo de Acuerdo entre el Reino de España y la República del Paraguay sobre participación en las elecciones municipales de los nacionales de cada país residentes en el territorio del otro, hecho en Madrid y Asunción el 13 de mayo de 2009) (BOE núm. 150, de 21 de junio de 2010), Corea (Canje de Notas constitutivo de Acuerdo entre el Reino de España y la República de Corea sobre participación en las elecciones municipales de los nacionales de cada país residentes en el territorio del otro, hecho en Madrid, Seúl el 16 de noviembre de 2010 y 26 de enero de 2011) (BOE núm. 160, de 6 de julio de 2010), Nueva Zelanda (Acuerdo entre el Reino de España y Nueva Zelanda sobre participación en determinadas elecciones de los nacionales de cada país residentes en el territorio del otro, hecho en Wellington el 23 de junio de 2009) (BOE núm. 5, de 6 de enero de 2010), y Bolivia (Canje de Notas constitutivo de Acuerdo entre el Reino de España y el Estado Plurinacional de Bolivia sobre participación en las elecciones municipales de los nacionales de cada país residentes en el territorio del otro, hecho en Madrid el 15 de septiembre de 2009) (BOE núm. 306, de 17 de diciembre de 2010).

Se han firmado acuerdos también con Argentina (Acuerdo por el que se autoriza la firma del Acuerdo entre el Reino de España y la República Argentina sobre voto en elecciones municipales de los nacionales argentinos en España y los nacionales españoles en Argentina, hecho en Madrid el 9 de febrero de 2009) (BOCG Serie A n ${ }^{\circ}$ 140, de 29 de mayo de 2009) y con Uruguay (Canje de Notas, de 30 de noviembre de 2009, constitutivo de Acuerdo entre el Reino de España y la República Oriental del Uruguay sobre participación en las elecciones municipales de los nacionales de cada país residentes en el territorio del otro) (BOCG Serie $\mathrm{A} \mathrm{n}^{\circ} 281$, de 26 de marzo de 2010), que aún no han entrado en vigor.

En otra esfera se enmarcan una serie de Tratados generales de Cooperación y Amistad celebrados con Argentina en 1988 (art. 9) (BOE núm. 205, de 28 de agosto de 1989); con Venezuela en 1990 (art. 11) (BOE núm. 170, de 16 de julio de 1992); con Uruguay en 1992 
(art. 15) (BOE núm. 182, de 1 de agosto de 1995) y con Colombia en 1992 (art. 13) (BOE núm. 182, de 1 de agosto de 1995). Todos ellos apelan a la necesidad de un acuerdo complementario que no se ha producido en ninguno de los casos citados hasta el momento. El acuerdo con Chile (BOE núm. 223, de 17 de septiembre de 1991), en cambio, no remite a ningún acuerdo complementario, especificando su artículo 17 que "se concederá a los nacionales de ambos países el derecho de voto en las elecciones municipales del Estado en que residan y del que sean nacionales, de conformidad con sus respectivas legislaciones".

Esto supone que en las elecciones municipales del 24 de mayo de 2015 podrán votar un total de 342.647 ciudadanos extracomunitarios, originarios de estos países.

\begin{tabular}{lrr} 
Nacionales de países con Acuerdos para elecciones \\
municipales, residentes en España, por país de nacionalidad \\
\hline País de nacionalidad & & Comunicaciones enviadas \\
\cline { 1 - 1 } TOTAL & & 342.647 \\
\hline Bolivia & & 1.474 \\
Cabo Verde & 11.499 \\
Chile & 88.685 \\
Colombia & 1.158 \\
Corea & 125.022 \\
\hline Ecuador & 370 \\
Islandia & 8.792 \\
Noruega & 194 \\
Nueva Zelanda & 15.172 \\
Paraguay & 42.772 \\
\hline Perú & 16 \\
\hline Trinidad y Tobago & & \\
\hline
\end{tabular}

Fuente: Instituto Nacional de Estadística

Para poder ejercer el derecho de voto en el municipio de su residencia habitual, los inmigrantes deberán figurar en el padrón municipal y estar inscritos en el censo electoral. Para realizar esa inscripción se requiere ser mayor de edad en la fecha de la votación; no estar privado del derecho de sufragio activo; tener el permiso de residencia en vigor; haber residido en España, legal e ininterrumpidamente durante, al menos, los cinco años anteriores a su solicitud de inscripción en el censo electoral, con la excepción de los noruegos para los que se requiere más de tres años y presentar la solicitud de inscripción en el plazo establecido. En estas elecciones este plazo se abrió el 1 de diciembre de 2014 y se ha extendido hasta el 15 de enero de 2015.

Si tenemos en cuenta el número de extranjeros que residen en España y los extranjeros que podrían votar en las elecciones municipales, constatamos que únicamente podrían hacerlo el 15,7 \%, realmente una cifra bastante baja. Dicho desde otra perspectiva, más del $84 \%$ de los extranjeros residentes en España no nacionales de un Estado miembro de la Unión Europea estarían privados del derecho de sufragio. Téngase en cuenta además que España ha celebrado acuerdos con Estados cuya presencia de nacionales en nuestro país y de españoles en ese Estado es muy reducida (así, por ejemplo, Trinidad y Tobago, Nueva Zelanda, Islandia), mientras no ha celebrado acuerdos con los Estados cuya presencia de nacionales en España es más numerosa (Marruecos). 


\section{Extranjeros en Régimen General. Principales nacionalidades}

\begin{tabular}{|c|c|c|c|c|c|}
\hline \multirow[b]{3}{*}{ Total } & & & \multicolumn{3}{|c|}{ Variacion (96) } \\
\hline & \multicolumn{2}{|c|}{$30-06-2014$} & \multirow{2}{*}{$\begin{array}{c}\text { Trimestral: } \\
\text { Respecto a } \\
\text { 31-03-2014 } \\
-1,52\end{array}$} & \multirow{2}{*}{$\begin{array}{c}\text { Acumulada: } \\
\text { Respecto a } \\
\text { 31-12-2013 } \\
-3,16\end{array}$} & \multirow{2}{*}{$\begin{array}{c}\text { Interanual: } \\
\text { Respecto a } \\
30-06-2013 \\
-5,95\end{array}$} \\
\hline & 2.181 .306 & 100,0096 & & & \\
\hline Marruecos & 738.984 & $33,89 \%$ & $-0,85$ & $-1,53$ & $-2,63$ \\
\hline China & 184.268 & $8,45 \%$ & 0,84 & 1,89 & 3,73 \\
\hline Ecuador & 183.241 & $8,40 \%$ & $-4,61$ & $-9,20$ & $-16,57$ \\
\hline Bolivia & 111.297 & $5,10 \%$ & $-4,10$ & $-8,60$ & $-15,40$ \\
\hline Colombia & 109.283 & $5,01 \%$ & $-4,92$ & $-10,58$ & $-20,68$ \\
\hline Uarania & 75.368 & $3,46 \%$ & 0,41 & 0,88 & 1,62 \\
\hline Pakistán & 67.502 & $3,10 \%$ & 0,20 & 0,61 & 2,35 \\
\hline Perú & 60.946 & $2,80 \%$ & $-6,75$ & $-13,34$ & $-23,60$ \\
\hline Argelia & 53.387 & $2,45 \%$ & $-0,38$ & $-1,02$ & $-1,93$ \\
\hline Senegal & 49.919 & $2,29 \%$ & 0,50 & 0,79 & 1,88 \\
\hline Paraguay & 40.054 & $1,84 \%$ & $-0,60$ & $-1,12$ & 0,09 \\
\hline Argentina & 39.190 & $1,80 \%$ & $-3,80$ & $-7,57$ & $-13,54$ \\
\hline Rep. Dorninicana & 36.063 & $1,65 \%$ & $-4,95$ & $-10,38$ & $-18,14$ \\
\hline Rusia & 32.244 & $1,48 \%$ & 1,77 & 3,08 & 6,30 \\
\hline India & 31.554 & $1,45 \%$ & 0,81 & 1,64 & 3,40 \\
\hline Resto de palses & 367.048 & $16,83 \%$ & $-0,78$ & $-1,69$ & $-3,22$ \\
\hline No consta & 958 & - & 2,46 & 3,57 & 4,93 \\
\hline
\end{tabular}

Fuente: Observatorio Permanente de la Inmigración

\section{C) Regulación de la Unión Europea}

La ciudadanía de la Unión Europea es un status reconocido a los nacionales de cualquiera de los 28 Estados miembros de la Unión. Con ella, se genera un concepto que pretende identificar a la población de un ente supranacional como la Unión Europea y, de alguna forma, incidir en el sentimiento de pertenencia que, todavía hoy, está muy lejos de ser una realidad. La justificación del reconocimiento del derecho de voto en las elecciones municipales a los ciudadanos europeos se hizo con vistas a facilitar una mejor integración de los ciudadanos de la Unión Europea en su país de acogida (Méndez Lago:133).

Hasta el momento, únicamente los ciudadanos de la Unión Europea pueden ejercer el derecho de sufragio pasivo en las elecciones municipales, además del activo. En ninguno de los Acuerdos celebrados y citados en el anterior epígrafe se reconoce la posibilidad de presentarse como candidato en estas elecciones. Pero lejos de ser un privilegio a considerar, no parece muy justificado que estos ciudadanos, si se los califica como europeos y, por tanto, como miembros de una misma ciudadanía, sólo puedan votar en las elecciones municipales, además de en las del Parlamento Europeo, y no en todas y cada una de las citas electorales previstas en España. Recurrir en este caso a la explicación del TC de que las elecciones municipales carecen de valor político, no sólo no está justificado, sino que supondría privar de carácter político a un derecho previsto y otorgado con este cariz a los ciudadanos de la Unión Europea.

A fecha de 30 de junio de 2014, se contabilizaban en nuestro país 2.724 .189 personas sujetas al régimen comunitario, de las que 2.357.627 son nacionales de cualquiera de los 28 países de la Unión Europea; el resto (366.562) son nacionales de terceros Estados a los que 
se les aplica el régimen comunitario, normalmente por tratarse de familiar de ciudadano comunitario.

\begin{tabular}{|c|c|c|c|c|c|}
\hline \multicolumn{6}{|c|}{ Extranjeros en Régimen Comunitario. Principales nacionalidades } \\
\hline & \multirow{2}{*}{\multicolumn{2}{|c|}{$30-06-2014$}} & \multicolumn{3}{|c|}{ Variacion (\%) } \\
\hline & & & \multirow{2}{*}{ 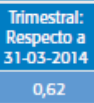 } & \multirow{2}{*}{$\begin{array}{c}\begin{array}{c}\text { Acumulada: } \\
\text { Respecto a } \\
\text { 31-12-2013 }\end{array} \\
1,23\end{array}$} & \multirow{2}{*}{$\begin{array}{c}\text { Interanual: } \\
\text { Respecto a } \\
\text { 30-06-2013 } \\
2,48\end{array}$} \\
\hline Total & 2.724 .189 & $100,00 \%$ & & & \\
\hline Ciudadanos comunitarios & 2.357 .627 & 86,5596 & 0,80 & 1,58 & 3,21 \\
\hline Rumanla & 940.252 & $34,52 \%$ & 0,72 & 1,30 & 1,97 \\
\hline Reino Unido & 269.756 & 9,9096 & 0,75 & 1,59 & 3,78 \\
\hline Italia & 210.304 & 7,7296 & 1,32 & 2,57 & 5,38 \\
\hline Bulgaria & 181.684 & $6,67 \%$ & 0,46 & 0,87 & 1,76 \\
\hline Alemania & 145.501 & $5,349 \%$ & 0,76 & 1,54 & 3,80 \\
\hline Portugal & 141.736 & $5,20 \%$ & 0,48 & 0,99 & 2,28 \\
\hline Francia & 120.023 & $4,41 \%$ & 1,30 & 2,93 & 6,16 \\
\hline Polonia & 89.533 & 3,2996 & 0,49 & 1,05 & 2,60 \\
\hline Palses Bajos & 48.415 & $1,78 \%$ & 1,32 & 2,64 & 5,46 \\
\hline Resto de palses & 210.423 & 7,7296 & 0,95 & 2,14 & 5,63 \\
\hline $\begin{array}{l}\text { Familiares nacionales de } \\
\text { terceros palses }\end{array}$ & 366.562 & 13,4696 & $-0,51$ & $-1,00$ & $-1,94$ \\
\hline Colombia & 38.703 & $1,42 \%$ & $-1,73$ & $-3,62$ & $-7,39$ \\
\hline Marruecos & 35.411 & $1,30 \%$ & 1,10 & 1,94 & 3,54 \\
\hline Rep. Dominicana & 31.341 & $1,15 \%$ & $-0,17$ & $-0,64$ & 0,44 \\
\hline Brasil & 27.577 & $1,01 \%$ & $-1,41$ & $-2,93$ & $-6,10$ \\
\hline Argentina & 24.953 & 0,9240 & $-2,28$ & $-4,74$ & $-9,40$ \\
\hline Cuba & 23.298 & $0,86 \%$ & $-1,01$ & $-1,80$ & $-3,04$ \\
\hline Resto de palses & 185.148 & $6,80 \%$ & $-0,17$ & $-0,12$ & $-0,23$ \\
\hline No consta & 131 & - & 0,77 & 6,50 & 11,97 \\
\hline
\end{tabular}

Fuente: Observatorio Permanente de la Inmigración

En las elecciones municipales del 24 de mayo de 2015 podrán votar los ciudadanos de la Unión Europea residentes en España que tengan 18 años o más ese día. Para poder votar se requiere haber manifestado previamente su voluntad de ejercer este derecho. Según datos del Instituto Nacional de Estadística estarían en esta situación un total de 418.187 electores. Además, la Oficina del Censo Electoral ha enviado comunicación a 422.008 que podrían votar pero que aún no han manifestado su intención de hacerlo.

\section{D) Régimen electoral}

El eslabón último para concretar el derecho de sufragio en nuestro país lo constituye la Ley Orgánica 5/1985, de 19 de junio, de Régimen Electoral General (LOREG).

En cuanto al sufragio activo, el artículo 176 LOREG precisa que los extranjeros residentes en España cuyos respectivos países permitan el voto a los españoles en las elecciones municipales en los términos de un tratado gozan del derecho de sufragio activo en las elecciones municipales españolas.

Asimismo, gozan del derecho de sufragio activo en las elecciones municipales todas las personas residentes en España que, sin haber adquirido la nacionalidad española: a) Tengan la condición de ciudadanos de la Unión Europea según lo previsto en el párrafo 2 del apartado 1 del artículo 8 del TCE; b) Reúnan los requisitos para ser elector exigidos en esta Ley para los españoles y hayan manifestado su voluntad de ejercer el derecho de sufragio activo en España. 


\begin{tabular}{|c|c|c|}
\hline Provincia & $\begin{array}{l}\text { Electores de la UE en } \\
\text { elecciones municipales }\end{array}$ & $\begin{array}{l}\text { Comunicaciones } \\
\text { enviadas }\end{array}$ \\
\hline TOTAL & 418.187 & 422.008 \\
\hline Alemania & 44.398 & 27.721 \\
\hline Austria & 2.160 & 2.140 \\
\hline Bélgica & 9.148 & 6.957 \\
\hline Bulgaria & 19.737 & 28.756 \\
\hline Chipre & 21 & 137 \\
\hline Croacia & 30 & 1.683 \\
\hline Dinamarca & 3.182 & 2.521 \\
\hline Eslovenia & 159 & 530 \\
\hline Estonia & 194 & 817 \\
\hline Finlandia & 2.647 & 3.357 \\
\hline Francia & 31.343 & 26.524 \\
\hline Grecia & 787 & 1.716 \\
\hline Hungría & 965 & 3.289 \\
\hline Irlanda & 4.207 & 4.598 \\
\hline Italia & 41.779 & 45.911 \\
\hline Letonia & 466 & 1.718 \\
\hline Lituania & 1.782 & 4.082 \\
\hline Luxemburgo & 174 & 154 \\
\hline Malta & 33 & 90 \\
\hline Países Bajos & 14.248 & 10.606 \\
\hline Polonia & 7.969 & 12.069 \\
\hline Portugal & 19.571 & 23.271 \\
\hline Reino Unido & 100.114 & 58.427 \\
\hline República Checa & 1.028 & 2.251 \\
\hline República Eslovaca & 863 & 1.679 \\
\hline Rumanía & 105.938 & 145.302 \\
\hline Suecia & 5.244 & 5.702 \\
\hline
\end{tabular}

Fuente: Instituto Nacional de Estadística

Por su parte, el art. 177 LOREG dispone que son elegibles en las elecciones municipales todas las personas residentes en España que, sin haber adquirido la nacionalidad española: a) Tengan la condición de ciudadanos de la Unión Europea según lo previsto en el párrafo 2 del apartado 1 del artículo 8 del TCE, o bien, sean nacionales de países que otorguen a los ciudadanos españoles el derecho de sufragio pasivo en sus elecciones municipales en los términos de un Tratado; b) Reúnan los requisitos para ser elegibles exigidos en esta Ley para los españoles; c) No hayan sido desposeídos del derecho de sufragio pasivo en su Estado de origen.

En relación con las elecciones al Parlamento Europeo, el artículo 210 LOREG precisa que gozan del derecho de sufragio activo todas las personas residentes en España que, sin haber adquirido la nacionalidad española: a) Tengan la condición de ciudadanos de la Unión Europea según lo previsto en el párrafo 2 del apartado 1 del artículo 8 del TCE; b) Reúnan los requisitos para ser elector exigidos en esta Ley para los españoles y gocen del derecho de sufragio activo en el Estado miembro de origen. Precisándose además que nadie podrá votar más de una vez en las mismas elecciones y que para ejercer tal derecho en España deberá haber optado previamente en tal sentido.

Por último, el art. 210 bis LOREG precisa que son elegibles en las elecciones al Parlamento Europeo todas las personas residentes en España que, sin haber adquirido la nacionalidad española: a) Tengan la condición de ciudadanos de la Unión Europea según lo previsto en el párrafo 2. del apartado 1 del artículo 8 del TCE; b) Reúnan los requisitos para ser elegibles exigidos en esta Ley para los españoles y sean titulares del derecho de sufragio pasivo en el Estado miembro de origen. 


\section{ANÁLISIS DE LAS "FRACASADAS" PROPUESTAS LEGISLATIVAS DE RECONOCIMIENTO DEL DERECHO DE SUFRAGIO DE LOS CIUDADANOS EXTRANJEROS EN ESPAÑA}

El 27 de septiembre de 2005 se presentó por parte del Grupo Parlamentario de Izquierda Verde-Izquierda Unida-Iniciativa per Catalunya Verds, una Proposición de Ley Orgánica para el reconocimiento del derecho de sufragio activo y pasivo a los ciudadanos extranjeros en España (BOCG Serie B Proposiciones de Ley, núm. 207-1, de 7 de octubre de 2005). En ella se proponía una modificación de la LO 8/2000 (art. 6) y varias modificaciones de la LOREG (arts. 2, 6, 176, 177, 210 y 210 bis). En el articulado se omitía la referencia a la exigencia de reciprocidad, si bien la disposición adicional segunda encomendaba al Gobierno el impulso del establecimiento de Tratados con el máximo número de Estados cuyas condiciones democráticas lo hicieran posible. Caducada con el fin de la VIII Legislatura, se presentó una iniciativa con el mismo contenido el 8 de abril de 2008.

Entremedio, se presentó la Proposición no de ley sobre la extensión del derecho a voto en las elecciones municipales a los extranjeros residentes legales, presentada el 10 de julio de 2006 por los Grupos Parlamentarios Socialista e IU-ICV (BOCG Serie D General, núm. 428, de 11 de septiembre de 2006, pág. 17-18), en cuya Exposición de Motivos se alude a la necesidad de favorecer la integración social de los inmigrantes de larga duración en el ámbito de la participación política y se afirma que el derecho al voto de los extranjeros en las elecciones municipales es "una exigencia democrática, que se corresponde con el espíritu y la letra de nuestra Constitución". Se hace referencia a los tratados y acuerdos generales con Argentina, Venezuela, Chile, Uruguay y Colombia en los que se reconoce el derecho de sufragio en las elecciones municipales de los residentes legales, si bien se remite la efectividad del derecho a lo que establezcan los convenios específicos o legislación de desarrollo. A partir de todo ello, se proponía que el Congreso de los Diputados instara al Gobierno a:

a) Proceder a la negociación y firma de acuerdos o convenios con los países con mayor número de nacionales residentes legales en España y, especialmente, con aquellos con los que ésta tiene relaciones históricas, políticas y culturales más estrechas, al objeto de que dichos nacionales puedan votar y ser elegidos en las elecciones municipales en España con arreglo al artículo 13.2 de la Constitución.

b) Solicitar del Consejo de Estado un informe sobre la aplicación del artículo 13.2 CE, a los efectos de la participación de los extranjeros residentes en España en las elecciones municipales y, particularmente, sobre la interpretación de los términos "criterios de reciprocidad" a que se refiere el precepto solicitado.

c) La firma y ratificación del Convenio europeo sobre participación de los extranjeros en la vida pública local, de 5 de febrero de 1992.

En esta iniciativa se hacía referencia a la Resolución del Parlamento Europeo sobre la situación de los derechos fundamentales en la Unión Europea [2000/2231 (INI)], en cuyos artículos 121 y 122 se recomienda a los Estados miembros que extiendan el derecho de sufragio activo y pasivo en las elecciones municipales europeas a los ciudadanos de terceros países que residan legalmente en el territorio de la Unión Europea desde hace como mínimo tres años y recomienda a los Estados miembros que ratifiquen el Convenio europeo sobre la participación de los extranjeros en la vida pública local, hecho en Estrasburgo el 5 de febrero de 1992, en vigor desde el 1 de mayo de 1997, cosa que aún no ha hecho España. 
Nada más comenzar la IX Legislatura, se presentó la Proposición de Ley Orgánica para el reconocimiento del derecho de sufragio activo y pasivo de los ciudadanos extranjeros en España (Grupo Parlamentario de Ezquerra Republicana-Izquierda Unida-Iniciativa per Catalunya Verds).

Esta iniciativa proponía el reconocimiento del derecho de sufragio activo y pasivo en las elecciones municipales y al Parlamento Europeo a los extranjeros que acrediten uno (elecciones municipales) o tres (elecciones al Parlamento Europeo) años de residencia o disfruten del estatuto de residencia permanente, reúnan los requisitos para ser electores exigidos en la LOREG y soliciten su inscripción en el Censo electoral. Esta iniciativa tampoco se consumó.

\section{DERECHO COMPARADO}

Son cinco las variables a considerar en relación con el reconocimiento del derecho sufragio de los extranjeros no comunitarios en Europa: a) el ámbito territorial (local o regional) para el que se reconoce el derecho; b) la extensión del derecho, es decir, si se trata sólo del derecho a elegir o también a ser elegido; c) la regulación estatal del derecho o la atribución autónoma por la propia administración territorial (generalmente, local) donde se va a ejercer; d) el período de residencia legal en el país de acogida exigido para el reconocimiento del sufragio; y e) la posibilidad de que los extranjeros formen partidos políticos para concurrir a las elecciones (Miravet, 2006:11).

Casi todos los Estados que han reconocido el derecho de voto únicamente lo reconocen en las elecciones locales, a excepción de Nueva Zelanda, que permite también este derecho en las elecciones generales. Por lo que no queda claro si el avance hacia el reconocimiento del derecho de voto se realiza a partir de un cuestionamiento del vínculo entre nacionalidad y derecho a participar en la toma de decisiones de una comunidad política, o si este proceso fundamentalmente se ve facilitado por una argumentación que resta valor político a las elecciones locales, más centradas en ejecución de competencias con un carácter supuestamente más gerencial o administrativo (Méndez Lago:130).

Desde la perspectiva europea varios datos son destacables. En 2010 había un total de 32,5 millones de personas residentes en la Unión Europea con nacionalidad extranjera. Alemania, país de larga tradición inmigratoria, aporta el 21,9 \% del total; España le sigue con un 17,4\%.

Son mayoría los Estados de la Unión Europea en los que se reconoce a nacionales de terceros Estados (no miembros) el derecho de sufragio activo o pasivo en las elecciones municipales (Bélgica, Dinamarca, Eslovaquia, Eslovenia, Estonia, Finlandia, Hungría, Irlanda, Lituania, Luxemburgo, Holanda, Portugal y Reino Unido). En cambio, el derecho de sufragio sigue reservado a los nacionales (y ciudadanos de la Unión) en Alemania, Austria, Bulgaria, Chipre, Francia, Grecia, Italia, Letonia, Rumanía, Malta y República Checa (Informe del Consejo de Estado:61).

En relación con los periodos de residencia previa exigidos, oscilan entre los cinco años (Bélgica, Estonia, Lituania, Luxemburgo u Holanda) y los tres años (Dinamarca o Suecia), aunque en algunos casos no se exige residencia previa (Hungría e Irlanda), o se establecen periodos variables en función del Estado de origen y del sufragio activo o pasivo (Portugal, Reino Unido y Finlandia) (Informe del Consejo de Estado:61-62).

Fuera de la Unión Europea, reservan a los nacionales el derecho de sufragio Liechtenstein, Rusia y Ucrania y en Iberoamérica, Costa Rica, Cuba, El Salvador, Guatemala, Honduras, México, Nicaragua, Panamá. 


\section{Países de la UE con más población extranjera. 2010}

\begin{tabular}{lr}
\hline UE-27 & 32.489 .000 \\
Alemania & 7.130 .919 \\
España & 5.663 .525 \\
Reino Unido & 4.362 .006 \\
\hline Italia & 4.235 .059 \\
Francia & 3.769 .016 \\
Bélgica & 1.052 .844 \\
Grecia & 954.784 \\
\hline Austria & 876.355 \\
Países Bajos & 652.188 \\
Suecia & 590.475 \\
\hline & Fuente: Eurostat
\end{tabular}

Brasil (con la excepción del reconocimiento del derecho de sufragio de los portugueses) y República Dominicana. En África, Argelia, Gambia, Ghana, Guinea Ecuatorial, Malí, Marruecos, Mauritania, Nigeria y Senegal y en Asia, China, Filipinas, India y Pakistán (Informe del Consejo de Estado:51-52).

El resto de Estados de la comunidad internacional, en mayor o en menor medida, reconocen el derecho de sufragio a los extranjeros (Informe del Consejo de Estado:52 y ss.).

\section{CONCLUSIONES}

La nacionalidad es el vínculo jurídico-político que liga a una persona física con un Estado, y hasta el momento ha sido el criterio fundamental para determinar la pertenencia a la comunidad política, entendida como el conjunto de individuos que se reconocen algún interés común básico y toman decisiones colectivas vinculantes. Reconocer el derecho de voto a los no nacionales se ha presentado por parte de algunos sectores como una "rebaja" de los privilegios de los ciudadanos nacionales de ese Estado, o incluso una amenaza a sus intereses, dado que, siguiendo con la equiparación anterior, por definición los nacionales de un Estado son quienes comparten ese interés, y de acuerdo con esa visión, incorporar a no nacionales implica incluir en la comunidad a personas que no tienen ese vínculo común que se presupone a los nacionales y admitir una suerte de "injerencia externa" (Méndez Lago:127).

Pocos discuten, sin embargo, que el sufragio puede actuar como un poderoso instrumento de integración, ya que obliga a los partidos políticos contendientes en los procesos electorales a tener en cuenta las demandas y necesidades peculiares de los extranjeros residentes y a buscar soluciones para sus problemas específicos (Informe del Consejo de Estado: 41). Las consecuencias de no tener reconocido el derecho de voto son claras: los inmigrantes permanecen al margen de la toma de decisiones sobre asuntos públicos, no "cuentan" y no son "tenidos en cuenta" (Méndez Lago:127).

La realización del ideal democrático podría y debería pasar por el reconocimiento de una ciudadanía sobre la base de la coparticipación y de la integración efectiva del individuo en el 
grupo social, apareciendo la residencia, siempre que sea aceptada, como el elemento relevante por antonomasia para su concesión (Esteban de la Rosa: 4).

La sustitución del requisito de nacionalidad por el de residencia a la hora de conferir el derecho de voto permite superar la paradoja que apunta Presno al señalar que, mientras que un español que lleva treinta años residiendo en el extranjero podrá votar en cualquier proceso electoral que se celebre en España, un extranjero que lleve el mismo tiempo residiendo en España, como mucho, podrá votar en elecciones municipales si es nacional de algún Estado miembro de la Unión Europea o algunos de los Estados con los que España ha celebrados Acuerdos (Presno, 2004).

\section{BIBLIOGRAFÍA}

ARCE JIMÉNEZ, C. (2012). Los derechos políticos de los residentes extranjeros: la ciudadanía inclusiva. Sevilla: Defensor del Pueblo Andaluz.

BIEDMA FERRER, J. M. (1995). "Presente y futuro del Derecho de sufragio de los inmigrantes en España", en http://www.acoes.es/pdf/Comunica.pdf.

CLOSA, C. (1995). "Citizenship of the Union and Nationality of Member Status", Common Market Law Review, 32: 487 y ss.

DURÁN MUÑOZ, R.; MARTÍN MARTÍNEZ, M. y RODRÍGUEZ, A. (2007). La participación política de los extranjeros: estado de la cuestión. Sevilla: Centro de Estudios Andaluces, Consejería de la Presidencia.

ESTEBAN de la ROSA, F. (2001). "Derechos de participación política y empadronamiento de los extranjeros en España (art. 6)", en M. Moya Escudero (coord.) Comentario sistemático a la Ley de extranjería (Lo 4/200 y Lo 8/2000). Granada, Comares, pp. 547-578, accesible en http://www.ugr.es / festeban/documentos/ART_6_COMENTARIO_SISTEMATICO.pdf.

HABERMAS, J. (1999). La inclusión del otro: Estudios de Teoría política. Barcelona: Paidós Ibérica.

INFORME DEL CONSEJO DE ESTADO sobre las propuestas de modificación del Régimen Electoral General, de 24 de febrero de 2009.

MÉNDEZ LAGO, M. "Los derechos políticos de los inmigrantes", en http://www.um.es/ campusdigital/Libros/textoCompleto/la\%20condicion\%20inmigrante/LA\%20CONDICION\%20INMIG RANTE\%20cap6.pdf, capítulo 6.

MIRAVET, P. (2006). “Algunos problemas para la participación cívica y política de los inmigrantes". Cuadernos electrónicos de Filosofía del Derecho, $\mathrm{n}^{\circ}$ 14, http://www.uv.es/CEFD/14/pmiravet.pdf.

MORRIS. L. (2002). Managing migration: civic stratification and migrant's rights, Londres, Routledge. ORTEGA GIMÉNEZ, A. (2011). «El derecho al voto de los ciudadanos extracomunitarios en las próximas elecciones municipales españoles de 2011», Fundación Alternativas.

ORTEGA GIMÉNEZ, A.; LÓPEZ ÁLVAREZ, A. y CANO ESQUIBEL, M. J. "A vueltas con la integración del inmigrante: la extensión del derecho al voto de los ciudadanos extranjeros en España", http://www.unavarra.es/digitalAssets/149/149682_1000003.1_Ortega_DerechoVotoExtranjeros.pdf.

PRESNO LINERAS, M. A. (2004a). "La representación política como derecho fundamental", en Bastida Freijedo, F. (coord.), Fundamentos. Cuadernos monográficos de Teoría del Estado, Derecho Público e Historia Constitucional, $\mathrm{n}^{\mathrm{o}} 3$ (La representación política), Oviedo: Junta General del Principado de Asturias.

PRESNO LINERAS, M. A. (2004b) "El reconocimiento de los derechos de participación política como forma de integración de los extranjeros", $4^{\circ}$ Congreso sobre la inmigración en España. Ciudadanía y participación.

SÁNCHEZ JIMÉNEZ, M. A. (2009). "El impulso del reconocimiento del derecho de sufragio de los inmigrantes a través de la vía legislativa", en Sánchez Lorenzo, S. La integración de los extranjeros. Un análisis transversal desde Andalucía. Barcelona: Atelier.

SANTOLAYA, P. y REVENGA SÁNCHEZ, M. (2007). Nacionalidad, extranjería y derecho de sufragio. Madrid: Centro de Estudios Políticos y Constitucionales. 


\title{
Breve currículo:
}

\begin{abstract}
Antonia Durán Ayago
Licenciada y Doctora en Derecho por la Universidad de Extremadura con Premio Extraordinario (2004). Es autora de dos monografías, La protección internacional del menor desamparado: régimen jurídico (Colex, 2004) y La protección de las pymes en el comercio internacional: propuestas de regulación (Atelier, 2008). Y coautora de los siguientes libros: Guía Legal Práctica de Extranjería (con Beatriz L. Carrillo Carrillo), Comares, 2006; Curso de Nacionalidad y Extranjería (con Javier Carrascosa González y Beatriz L. Carrillo Carrillo), Colex, $2^{\text {a }}$ edición 2008 y Aplicación práctica del Derecho internacional privado: casos y soluciones (con Pilar Maestre Casas y María del Mar Velázquez), Ratio Legis, $3^{\mathrm{a}}$ Edición, 2011. Es autora además de numerosos artículos y capítulos de libros sobre distintas cuestiones del Derecho internacional privado, preferentemente en materia de Derecho de familia.
\end{abstract}

